\title{
Pathophysiology of visceral pain*
}

\author{
Fisiopatologia da dor visceral
}

\author{
Fernando Cervero ${ }^{1}$ \\ ${ }^{*}$ Received from McGill University, Montreal, Quebec, Canada.
}

DOI 10.5935/1806-0013.20140032

\section{ABSTRACT}

BACKGROUNDS AND OBJECTIVES: Visceral pain shows many pathophysiological properties that make this form of pain unique, not only because of the clinical properties of the sensation but also because the neurobiological mechanisms that mediate the sensory process. This study aimed at reviewing the pathophysiology of visceral pain.

CONTENTS: The activation and sensitization of visceral nociceptors are heavily influenced by the secretory and motor properties of the microenvironment where the sensory receptors are located. In some cases, epithelial cells can play a direct role in the activation of primary sensory neurons. Subclinical alterations of the visceral epithelium can contribute to enhanced visceral sensitivity. Central hypersensitivity induced by visceral activation can be caused by mobilization of AMPA receptors from the cytosol to the membrane of nociceptive neurons. In addition, functional pain syndromes, such as the Irritable Bowel Syndrome, could be triggered or maintained by hormonal alterations, particularly those involving sex hormones such as estrogen.

CONCLUSION: The neurobiological mechanisms that mediate visceral pain are sufficiently unique to preclude interpreting visceral pain conditions purely as a direct extrapolation of what we know about somatic pain. The functional properties of visceral nociceptors are different from those of their somatic counterparts and the microenvironment where visceral nociceptors are located, and especially the motor and secretory functions of organs like the gut, play a key role in the activation and sensitization of visceral sensory receptors.

Keywords: Pathophysiology, Review, Visceral pain.

1. Alan Edwards Centre for Research on Pain McGill University, Montreal, Quebec, Canada.

Submitted in February 04, 2014

Accepted for publication in May 26, 2014.

Conflict of interests: none.

Correspondence to:

Prof. Fernando Cervero

Anesthesia Research Unit, McGill University, McIntyre Medical Bldg. Room 1207

3655 Promenade Sir William Osler

Montreal, Quebec H3G 1Y6, Canada.

E-mail: fernando.cervero@mcgill.ca

(C) Sociedade Brasileira para o Estudo da Dor

\section{RESUMO}

JUSTIFICATIVA E OBJETIVOS: A dor visceral apresenta muitas propriedades fisiopatológicas que fazem dela única, não apenas devido às propriedades clínicas da sensação, mas também devido aos mecanismos neurobiológicos que mediam o processo sensorial. O objetivo deste estudo foi rever a fisiopatologia da dor visceral.

CONTEÚDO: A ativação e a sensibilização dos nociceptores viscerais são altamente influenciadas pelas propriedades secretórias e motoras do microambiente onde os receptores sensoriais estão localizados. Em alguns casos, as células epiteliais podem ter uma função direta na ativação de neurônios sensoriais primários. Alteraçôes subclínicas do epitélio visceral podem contribuir para o aumento da sensibilidade visceral. A hipersensibilidade central induzida pela ativação visceral pode ser causada pela mobilização de receptores AMPA do citosol para a membrana de neurônios nociceptivos. Além disso, síndromes dolorosas funcionais, como a Síndrome do Intestino Irritável, podem ser provocadas ou mantidas por alteraçóes hormonais, especialmente aquelas envolvendo hormônios sexuais, como o estrógeno.

CONCLUSÃO: Os mecanismos neurobiológicos que mediam a dor visceral são suficientemente únicos para excluir a possibilidade de interpretar condiçóes de dor visceral puramente como a extrapolação direta do que sabemos sobre dor somática. As propriedades funcionais dos nociceptores viscerais são diferentes das dos nociceptores somáticos e o microambiente onde os nociceptores viscerais estão localizados, e principalmente as funçóes motoras e secretórias de órgãos como o intestino, têm função importante na ativação e sensibilização de receptores viscerais sensoriais.

Descritores: Dor visceral, Fisiopatologia, Revisão.

\section{INTRODUCTION}

Visceral pain is an important component of the normal sensory repertoire of all human beings, a prominent symptom of many clinical conditions and one of the most frequent reasons for patients to seek medical attention. The traditional view of visceral pain considers it to be simply a variant of somatic pain. However, the more we know about the mechanisms of somatic and visceral sensation the more we realize that these two processes have important differences. The mechanisms of visceral pain are likely to differ between organs and systems but apart from the specifics of the individual viscus there are two common principles that apply to all forms of visceral pain. First, the psychophysics of visceral 
pain differs from that of somatic pain and needs to be carefully examined, as the characteristics of pain of internal origin will tell us much about the underlying cause. Second, the neurological mechanisms of somatic pain cannot be extrapolated to visceral pain without qualification.

Visceral pain has clinical features that make it unique and different from somatic pain ${ }^{1}$. These are: i) visceral pain is not evoked from all viscera, ii) it is not linked to visceral injury, iii) it is referred to other, often remote, locations, iv) it is diffuse and poorly localised and v) it is accompanied by exaggerated motor and autonomic reflexes. The mechanisms responsible for these clinical features of visceral pain are also unique. Properties i and ii are due to the functional properties of the peripheral receptors that innervate visceral organs and to the fact that many viscera are innervated by receptors whose activation does not evoke conscious perception and therefore are not sensory receptors in a strict sense. Properties iii, iv and v are explained by the central organisation of visceral nociceptive mechanisms, particularly by the lack of a separate visceral sensory pathway in the spinal cord and brain and to the very low proportion of visceral afferent fibres compared to those of somatic origin ${ }^{1}$.

The neurobiological mechanisms responsible for somatic and visceral hyperalgesia share some common features but they also have important differences. Traditionally two forms of hyperalgesia, primary and secondary, have been considered (Figure 1A). Primary hyperalgesia occurs at the site of injury and it is the consequence of increased input from nociceptors sensitized by the originating stimulus. These sensitized nociceptors send enhanced afferent discharges to the CNS thus evoking increased pain from the primary hyperalgesic area and contributing to the alterations in central processing that are, in turn, responsible for secondary hyperalgesia ${ }^{1}$.
Secondary hyperalgesia is usually defined as an increased sensitivity to pain occurring in areas adjacent or even remote to the site of injury. We know that secondary hyperalgesia is the result of an alteration in the central processing of impulses from lowthreshold mechanoreceptors, such that, these impulses are able to activate nociceptive neurons, thus evoking pain. The basic model of visceral hyperalgesia shown in figure $1 \mathrm{~A}$ includes the peripheral origin of primary hyperalgesia due to nociceptor sensitization and the alteration in the central processing of afferent impulses from low threshold mechanoreceptors that results in referred secondary hyperalgesia. This alteration is initially triggered and later maintained by the enhanced afferent discharges from the primary hyperalgesic area. In the case of referred visceral hyperalgesia the primary focus is located in an internal organ, where nociceptors are sensitized by the originating stimulus and send enhanced discharges to the central nervous system (CNS). There, these impulses trigger and maintain a secondary hyperalgesic area that, in this case, is referred to the surface of the body ${ }^{1}$. The fundamental neurobiological mechanism is therefore similar in somatic and visceral hyperalgesia and in both cases includes a peripheral component of enhanced activity from nociceptors and a central component of alteration in the central processing of low threshold inputs. However, in the case of visceral hyperalgesia the peripheral component can generate a secondary hyperalgesic state that is remote from the originating locus and produces a sensory alteration mediated by an alteration in central processing. In the case of functional pain syndromes, this referred or secondary hyperalgesia can occur as a consequence of the activation of the central mechanisms by genetic, hormonal or metabolic factors in the absence of a clear peripheral drive (Figure $1 \mathrm{~B})^{1}$.

This study aimed at reviewing the pathophysiology of visceral pain

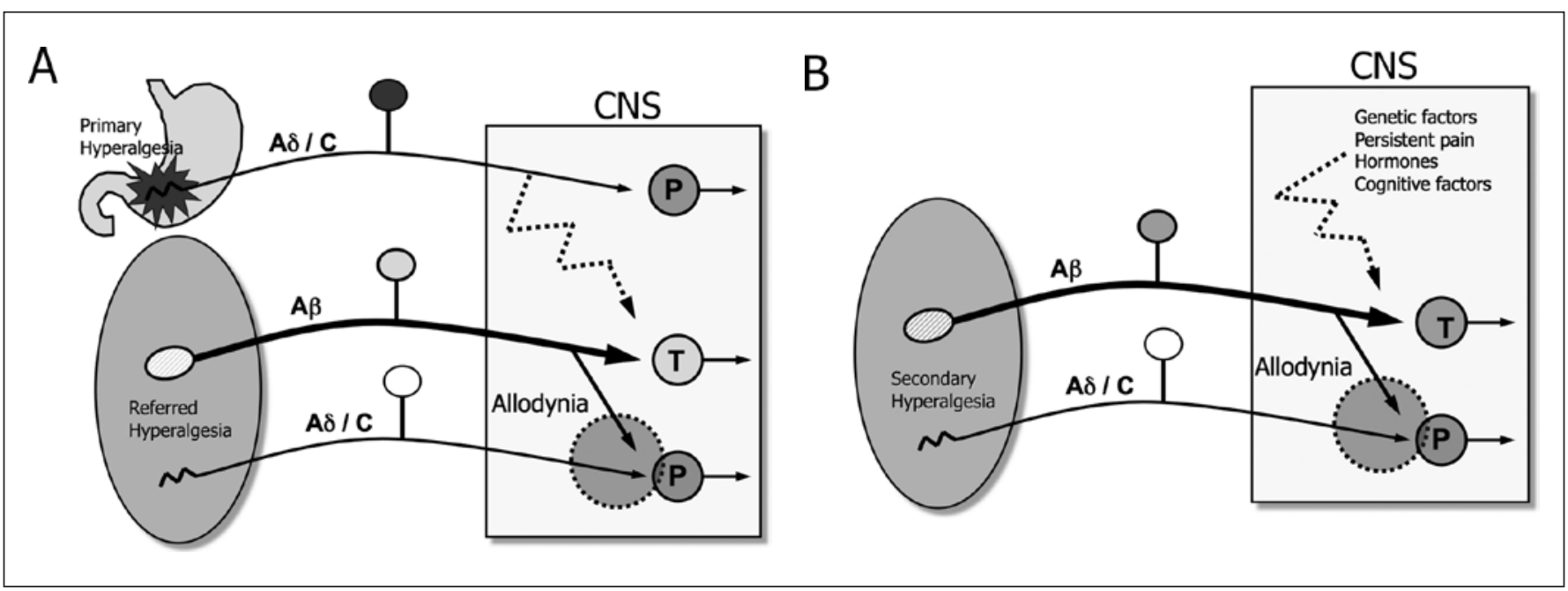

Figure 1. A: Diagram representing the basic mechanisms of visceral pain and of primary and secondary visceral hyperalgesia. Visceral pain and primary hyperalgesia are produced by the stimulation of nociceptors connected to $A \delta$ and $C$ afferent fibers which activate pain pathways $(P)$ in the CNS. Referred secondary hyperalgesia is produced by stimulation of tactile receptors connected to $A \beta$ afferents which normally activate tactile (T) pathways but that as a consequence of the amplification of the nociceptive input from the injured area can now access pain neurons (P) causing touch-evoked pain (allodynia). B: Functional pain states can be triggered by a variety of factors (genetic, hormonal etc) such that the central alteration of sensory processing that mediates referred secondary hyperalgesia is activated in the absence of a peripheral drive from nociceptors 


\section{SENSITIZATION OF VISCERAL NOCICEPTORS}

Tissue injury induces a process of peripheral sensitisation whereby the excitability of the nociceptors is increased and their threshold lowered. Sensitisation is an important neuronal mechanism underlying primary hyperalgesia at the site of injury or inflammation ${ }^{1}$ (Figure 1A). Pain is the only sensation that can be evoked from most internal organs and even innocuous sensations of rectal or bladder fullness can rapidly evolve to discomfort and pain if maintained. The afferent innervation of viscera consists mainly of unmyelinated fibres without specialized receptor endings. The encoding properties of visceral sensory receptors include discrete ranges in the innocuous and noxious domains as well as intensity-encoders that are activated by a full range of stimulus intensities. These are just a few samples of the many mechanistic differences between somatic and visceral pain. Perhaps the most striking feature of the activation and sensitization of visceral nociceptors is the relation of these processes to the microenvironment of the visceral sensory receptor. The complex motor and secretory functions of internal organs, and especially of the gut, play a determining role in the activation of visceral nociceptors and in their ability to enhance their responsiveness in hyperalgesic states. To understand this process may throw new light on the pathophysiology of visceral hyperalgesic states, particularly of those, such as IBS, characterized by an absence of demonstrable peripheral damage. It is possible that a small alteration of the microenvironment of the sensory receptor induces hypersensitivity of the nociceptor that in turn triggers the hyperalgesic state.

There is evidence that such processes can occur in the gut, where visceral nociceptors are located in close proximity to epithelial and smooth muscle cells that can alter their functions in chronic inflammatory states. One of the locations where this effect of the microenvironment of the sensitivity of visceral receptors is best know is in the urinary bladder, where a clear role for the urothelium in sensory transduction has been identified. The bladder and ureters, like the gut, are hollow organs from which intense pain sensations can be evoked. In the case of the bladder distension by urine evokes an initial sensation of fullness that rapidly evolves to discomfort and pain if the bladder is over distended or if it becomes hyperactive. In recent years a new body of evidence has come to light pointing to the bladder epithelial cells, the urothelium, as key players in the transduction of sensory events ${ }^{2}$. The urothelium, like the epithelium that covers the gut, can act as a barrier but also has dynamic properties, including some related to the signalling of sensory events. For instance it is known that these epithelial cells release ATP following stimulation of

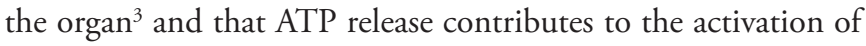
sensory afferents by acting on P2X3 receptors located in unmyelinated primary afferents ${ }^{4}$. This gives the epithelial cover of the gut or the bladder an almost neuron-like role in sensory activation. It is also known that urothelial cells express TRPV1 receptors, the endogenous receptor for the active principle of hot peppers 5 . TRPV1 receptors are highly expressed in the mucosa and muscle layers of the lower urinary $\operatorname{tract}^{6}$ and are localised on unmyelinated afferent fibres that also express Substance P (SP) and
CGRP. Birder et al. ${ }^{7}$ have also shown that TRPV1 is expressed not only by the afferent fibres located close to the urothelium but also by the urothelial cells themselves. They demonstrated that exogenously applied capsaicin or its potent analog resiniferatoxin increased intracellular $\mathrm{Ca} 2+$ and evoked $\mathrm{NO}$ release in urothelial cells by a process that required TRPV1 receptors. Mice lacking TRPV1 receptors show a reduction of ATP release by urothelial cells and a number of alterations in the expression of the micturition reflex indicative of a critical role of urothelial TRPV1 receptors in physiological process triggered by mechanical distension of the bladder ${ }^{8}$.

These studies have revealed a novel mechanism for the transduction of sensory stimuli, including those that may evoke pain, by the lower urinary tract. Urothelial cells can be activated by vanilloids and other TRPV1 agonists and this would produce the release of ATP to the subepithelial space. The same stimuli can also activate directly the TRPV1 receptors located in the endings of afferent fibres and, additionally, the ATP released by the urothelium will also stimulate $\mathrm{P} 2 \mathrm{X} 3$ receptors in these afferents which in turn will evoke sensory events, such as fullness or pain, and reflex activation of bladder activity (Figure 2).

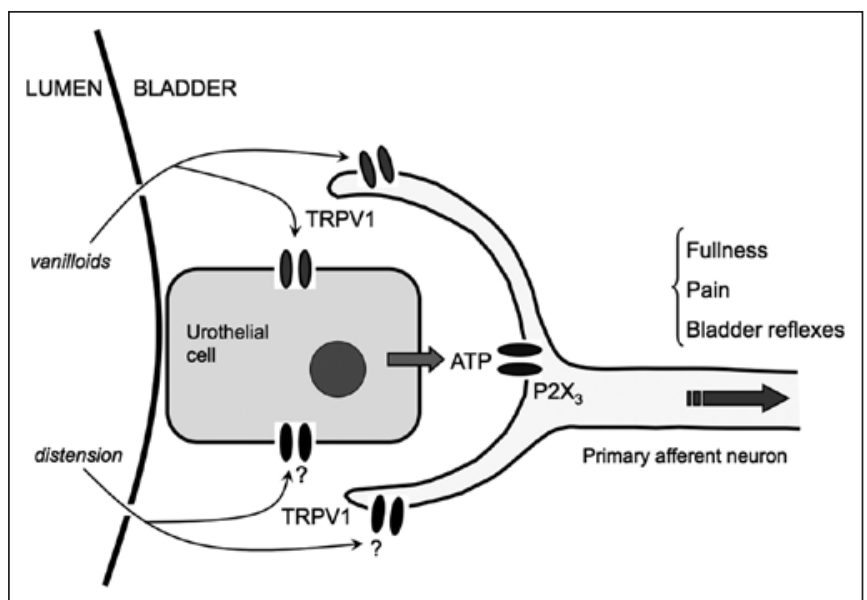

Figure 2. The characteristics of visceral sensory receptor activation are determined by the properties of the microenvironment. The figure shows a schematic diagram of the role of the urothelium in the signalling of sensory events. Urothelial cells contain TRPV1 receptors that are activated by vanilloids and other TRPV1 agonists causing the release of ATP, which in turn activates $\mathrm{P} 2 \mathrm{X} 3$ receptors in sensory afferents. Vanilloids also activate directly TRPV1 receptors located in these afferents. Distension is known to cause a TRPV1-dependant release of ATP from urothelial cells via an unknown mechanism

\section{VISCERAL HYPERSENSITIVITY AND REFERRED HYPERALGESIA}

Persistent visceral pain is mediated by an enhanced sensitivity of nociceptive neurons in the CNS. Unlike somatic pain, visceral pain can be expressed by increased pain and discomfort in areas of the body remote, and usually superficial, from the diseased viscus, a process known as referred hyperalgesia. In certain pathological conditions, referred hyperalgesia can be the only expression of underlying visceral disease. These areas of referred hyperalgesia are maintained by an enhanced afferent drive from 
the primary focus, due to the sensitization of peripheral visceral nociceptors, and are the consequence of altered sensory processing by the CNS (Figure 1A). The patterns of referred hyperalgesia are closely associated with the originating focus and are therefore a valuable clinical tool for the diagnosis of many forms of visceral disease.

The most popular interpretation of the mechanisms of referred hyperalgesia is based on the idea of central sensitization whereby CNS neurons become sensitized by the enhanced afferent drive from the primary focus. The consequences of this hyperexcitability would be enhanced pain sensitivity from the originating viscus, a general increase in motor and autonomic reactions and the appearance of areas of hyperalgesia in the somatic areas whose afferent innervation converges in the spinal cord with that of the damaged viscus. Central sensitization is the result of synaptic plasticity and is a memory trace of previous painful stimuli (for review see ${ }^{9,10}$. One of the best-characterized examples of synaptic plasticity in the mammalian nervous system is activity-dependent long-term potentiation (LTP), whereby brief, intense conditioning stimuli produce prolonged enhancement of responses to subsequent stimuli. LTP can be evoked by electrical stimulation in the population of superficial spinal cord neurons that mediate hyperalgesia ${ }^{11}$. It can also be induced in intact, anaesthetized rats by natural pain-producing stimuli ${ }^{12}$ and an LTPlike enhancement in pain sensitivity can be provoked in human subjects by high frequency electrical stimulation of the skin ${ }^{13}$. Thus it is likely that an LTP-like process underlies the generation of a hyperalgesic state. A number of potential molecular targets have been recently associated with the process of CNS sensitization and synaptic plasticity and some of them have been specifically identified as being related to the development of viscerally induced hyperalgesic states.

Potentiation of spinal nociceptive transmission by synaptic delivery of AMPA receptors, via an NMDA receptor- and $\mathrm{Ca}(2+)$ / calmodulin-dependent protein kinase II (CaMKII)-dependent pathway, has been proposed to underlie certain forms of hyperalgesia. To examine AMPA-receptor trafficking in spinal neurons after natural activation of the pain pathway in adult animals in vivo, we compared control mice with mice in which visceral pain and hyperalgesia was induced by intracolonic capsaicin ${ }^{14}$. Subcellular fractionation of proteins from the lumbrosacral spinal cord was followed by immunoblotting with specific antibodies against GluR1 and GluR2/3 AMPA-R subunits. There was a pronounced increase in the abundance of the AMPA-R subunit GluR1 in the synaptosomal membrane fraction with a peak 3.7-fold increase 180 min after treatment and a corresponding decrease in the levels in the cytosolic fraction. In contrast to the pronounced and prolonged effects of the painful visceral stimulus on GluR1 distribution, capsaicin treatment had no effect on the intracellular distribution of GluR2/3 in spinal tissue (Figure 3A).

We found that referred hyperalgesia was inhibited by pretreatment with Brefeldin A applied topically to the spinal cord (Figure 3B), whilst it did not have analgesic effects in naïve animals ${ }^{14}$. Brefeldin $\mathrm{A}$ is a fungal metabolite used as an antibiotic that specifically and reversibly blocks protein transport from the endoplasmic reticulum to the Golgi apparatus thereby inhibiting exocytosis $^{15}$ and also has the advantage of low toxicity. Brefeldin $A$ at the doses used in the behavioral experiment clearly inhibited the trafficking of GluR1 subunits to the membrane, thus GluR1 recruitment may contribute to the development and expression of visceral hyperalgesia.

\section{Functional abdominal pain}

Abdominal pain syndromes such as Inflammatory Bowel Disease (IBD) and Irritable Bowel Syndrome (IBS) generate two different kinds of visceral pain: organic and functional. The organic pain of IBD is the consequence of an inflammatory lesion of the gut that directly activates its sensory innervation. This kind of pain is due

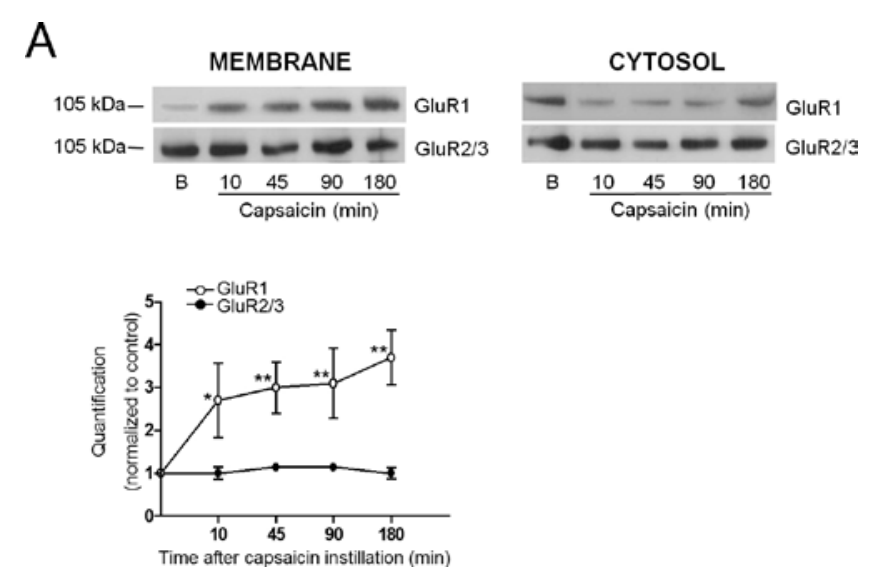

B

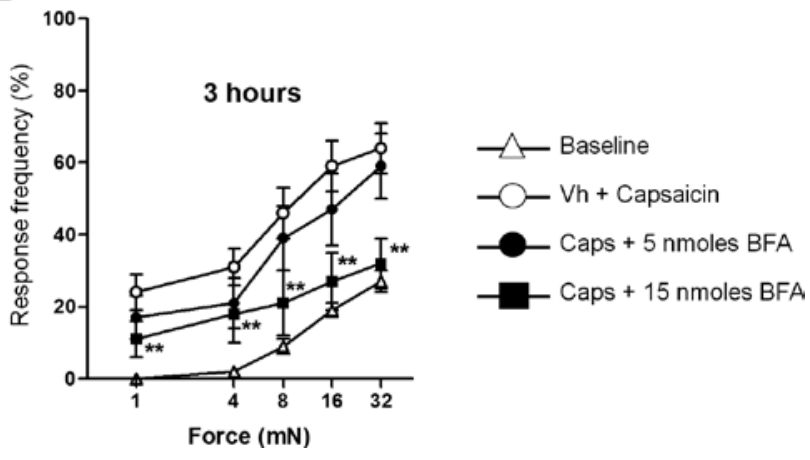

Figure 3. Molecular mechanisms of visceral hyperexcitability in the spinal cord. AMPA trafficking induced by a visceral noxious stimulus. A: Time course of subcellular distribution of GluR1 and GluR2/3 in the plasma membrane fraction and in the cytosolic fraction. Lanes marked 'B' in the immunoblots contain control (basal) tissue. The figure below shows quantification of GluR1 and GluR2/3 normalized to levels detected in control spinal tissue, which has the arbitrary value of " 1 ", run on the same gel; $n=4$ per time point. Asterisks indicate those groups that were significantly different from control levels $\left({ }^{*} p<0.05\right.$ and $\left.{ }^{* *} p<0.01\right)$. B: Responses to mechanical stimulation of the abdomen with von Frey hairs of five intensities. Data are shown as mean percent response frequency $( \pm$ SEM) before (baseline) and at various time points after intracolonic instillation of $0.1 \%$ capsaicin or two concentrations of brefeldin A. Asterisks indicate responses that were significantly different from baseline $(p<0.01)$. Data from ${ }^{14}$ 
to sensitization of the local sensory afferents, and to the processing of these enhanced signals by CNS mechanisms that amplify them and maintain an increased excitability of central neurons. On the other hand, the functional pain of IBS and other such conditions appears in the absence of demonstrable pathology of the gut or of their associated nerves. This kind of pain is commonly interpreted as a consequence of hypersensitivity of visceral nociceptive pathways, either of the sensory receptors in the periphery or of the central neurons. However, the pathophysiology of visceral hypersensitivity is far from clear, and there is ongoing discussion as to whether there is a peripheral focus that can be identified at the origin of visceral hypersensitivity ${ }^{16}$ or if the process is due to cognitive and affective factors that alter central processing of visceral sensory signals ${ }^{17}$. Because functional abdominal pain conditions are highly prevalent in women, it has been suggested that the pain correlates with the levels of circulating estrogens rather than with an organic disease of an abdominal or pelvic organ ${ }^{18,19}$.

There is some controversy in the literature as to whether estrogen has pro-nociceptive or anti-nociceptive properties in both humans and animals. It is well documented that there are gender differences in pain sensitivity, with females showing increased sensitivity to pain and a higher incidence of certain chronic pain syndromes ${ }^{20}$. These observations have led some investigators to the belief that estrogen is a pro-nociceptive hormone, responsible for the increased pain sensitivity of females. However, this notion has been difficult to prove in women as the data have generally shown an antinociceptive action of estrogen in both normal females and in those suffering from chronic pain ${ }^{21,22}$. A comprehensive review of the literature on the relationship between the menstrual cycle and pain sensitivity in humans ${ }^{23}$ concluded that numerous methodological inconsistencies made it difficult to draw conclusions about the relationship of female sex hormones with pain perception.
Animal studies have also produced contradictory results regarding the effects of estrogen on pain sensitivity. Using a variety of acute noxious stimuli and acute administration of estrogen several studies have reported an increase in the viscero-motor and neuronal responses to colorectal distension ${ }^{24}$, a sensitization of visceral afferents that innervate the uterine cervix ${ }^{25,26}$ and an amplification of pain responses to uterine cervical distension ${ }^{27}$. On the other hand there are also reports of increases in pain sensitivity in ovariectomized (OVX) rats that could be reversed or reduced by exogenous administration of estrogen ${ }^{28-30}$. It has also been described that the selective estrogen receptor-b agonist ERB-041 is antihyperalgesic in rat models of chemical and inflammatory pain ${ }^{31}$. These reports would indicate that estrogen could induce an increase in endogenous anti-nociception and thus reduce pain sensitivity.

Over the last few years we have developed an animal model of functional abdominal pain in ovariectomized adult mice ${ }^{32,33}$. These animals develop a chronic abdominal hyperalgesic state after ovariectomy (OVX) (Figure 4A) characterized by mechanical hyperalgesia and allodynia restricted to the abdominal and pelvic regions and to the hind limbs but sparing the rest of the body. Thermal and visceral hyperalgesia are also present in these animals. This hyperalgesic state appears 4 to 5 weeks after OVX and persists for several weeks thereafter. A particularly prominent feature of this model is a robust visceral hyperalgesia of early onset and long duration.

A striking aspect of the OVX-induced hyperalgesic state is its sensitivity to estrogen replacement therapy. Administration of exogenous estrogens to OVX animals by means of slow-release pellets containing 17-b estradiol can either prevent the development of the hyperalgesic state or reverse it back to normal once it has developed (Figure 4, A and B). Because of the clinical features of the hyperalgesia and its sensitivity to exogenous estrogen we have
A

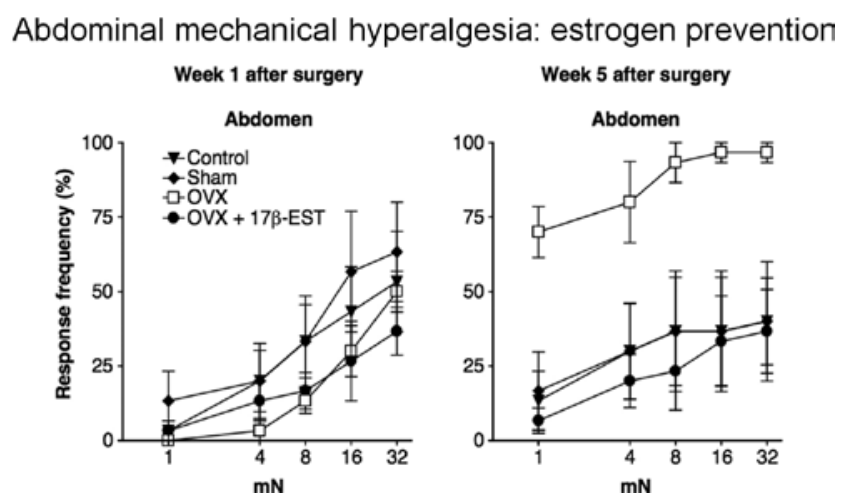

B

Abdominal mechanical hyperalgesia: estrogen reversal
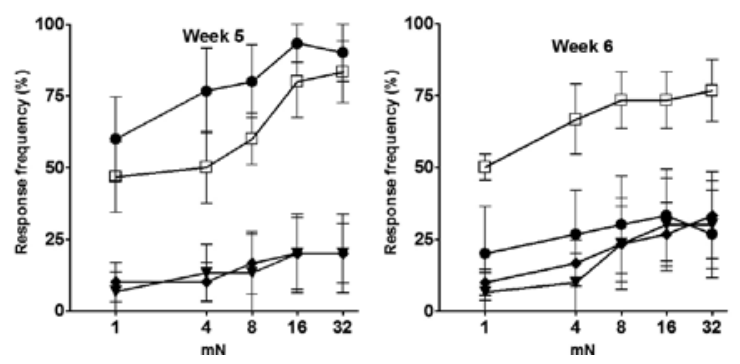

Figure 4: Estrogen prevention and reversal of the abdominal hyperalgesic state induced by ovariectomy (OVX). A: Responses to mechanical stimulation (von Frey hairs) of the abdomen in ovariectomized mice to which slow release pellets containing $17 \beta$-estradiol (OVX+17 $\beta$-estradiol) or the vehicle only (OVX) had been implanted one week after surgery. The same animals were tested one week and five weeks after surgery. Note that estrogen-replacement after ovariectomy prevents the development of the hyperalgesic state. B: Estrogen reversal of mechanical hyperalgesia. Data are presented as the responses to mechanical stimulation of the abdomen (von Frey hairs), in control, sham operated and OVX mice to which slow release pellets containing $17 \beta$-estradiol (OVX+estrogen) or the vehicle only (OVX) had been implanted at the end of week 5 post OVX. The same animals were tested one, five, six and ten weeks after surgery. Note that all OVX mice develop a hyperalgesic state by week 5 after OVX but that the group treated with estrogen at the end of week 5 (but not those treated with placebo) reverts to normal within one week. Data from ${ }^{32,33}$ 
suggested that OVX-induced hyperalgesia mimics the process that underlies functional abdominal pain disorders in women, particularly those in which no primary lesion of an abdominal or pelvic organ can be found and that show a slow onset, a hormonal modulation and a trend towards chronification ${ }^{32,33}$.

\section{CONCLUSION}

The neurobiological mechanisms that mediate visceral pain are sufficiently unique to preclude interpreting visceral pain conditions purely as a direct extrapolation of what we know about somatic pain. The functional properties of visceral nociceptors are different from those of their somatic counterparts and the microenvironment where visceral nociceptors are located, and especially the motor and secretory functions of organs like the gut, play a key role in the activation and sensitization of visceral sensory receptors. All forms of visceral pain include the development of a hyperalgesic state that originates from the internal organ that has been damaged or inflamed and is referred to a remote and superficial region of the body. In some cases visceral hyperalgesia appears in the absence of an identifiable peripheral cause, perhaps as a consequence of the sensitization and hyperexcitability of visceral afferents evoked by subclinical changes in their microenvironment. Hyperalgesia is the most prominent feature of the visceral pain process and is the expression of hypersensitivity of the pain pathway induced by the sensitization of the peripheral receptors that signal visceral sensory events or of the neurons that transmit and process this sensory information to the CNS. A process of synaptic plasticity, of which several molecular components have already been identified, mediates the central amplification of the visceral afferent signals that leads to the hypersensitivity of central neurons. In addition to the hyperalgesia triggered as a consequence of the injury or inflammation of an internal organ, there are also functional pain states, characterized by pain reported from the abdominal or pelvic cavities but in the absence of a demonstrable peripheral cause. Although not much is known about the causes of such states it is thought that hypersensitivity of peripheral sensory receptors or an enhanced responsiveness of central visceral pathways may be responsible for such functional pain states. Circulating sex hormones, particularly estrogen, may also have a role in the development and maintenance of functional pain syndromes in women.

\section{REFERENCES}

1. Cervero F, Laird JM. Visceral pain. Lancet. 1999;353(9170):2145-8.

2. Caterina MJ. Vanilloid receptors take a TRP beyond the sensory afferent. Pain. 2003;105(1-2):5-9.

3. Ferguson DR, Kennedy I, Burton TJ. ATP is released from rabbit urinary bladder epithelial cells by hydrostatic pressure changes--a possible sensory mechanism? J Physiol. 1997;505(Pt 2):503-11.
4. Cockayne DA, Hamilton SG, Zhu QM, Dunn PM, Zhong Y, Novakovic S, et al Urinary bladder hyporeflexia and reduced pain-related behaviour in P2X 3 -deficient mice. Nature. 2000;407(6807):1011-5.

5. Caterina MJ, Julius D. The vanilloid receptor: a molecular gateway to the pain pathway. Ann Rev Neurosci. 2001;24:487-517.

6. Avelino A, Cruz C, Nagy I, Cruz F. Vanilloid receptor 1 expression in the rat urinary tract. Neuroscience. 2002;109(4):787-98.

7. Birder LA, Kanai AJ, de Groat WC, Kiss S, Nealen ML, Burke NE, et al. Vanilloid receptor expression suggests a sensory role for urinary bladder epithelial cells. Proc Natl Acad Sci U SA. 2001;98(23):13396-401.

8. Birder LA, Nakamura Y, Kiss S, Nealen ML, Barrick S, Kanai AJ, et al. Altered urinary bladder function in mice lacking the vanilloid receptor TRPV1. Nat Neurosci. 2002;5(9):856-60.

9. Sandkuhler J. Learning and memory in pain pathways. Pain. 2000;88(2):113-8.

10. Ji RR, Kohno T, Moore KA, Woolf CJ. Central sensitization and LTP: do pain and memory share similar mechanisms? Trends Neurosci. 2003;26(12):696-705.

11. Ikeda H, Heinke B, Ruscheweyh R, Sandkühler J. Synaptic plasticity in spinal lamina I projection neurons that mediate hyperalgesia. Science. 2003;299(5610):1237-40.

12. Sandkühler J, Liu X. Induction of long-term potentiation at spinal synapses by noxious stimulation or nerve injury. Eur J Neurosci. 1998;10(7):2476-80.

13. Klein T, Magerl W, Hopf HC, Sandkühler J, Treed RD. Perceptual correlates of nociceptive long-term potentiation and long-term depression in humans. J Neurosci. 2004;24(4):964-71.

14. Galan A, Laird JM, Cervero F. In vivo recruitment by painful stimuli of AMPA recepto subunits to the plasma membrane of spinal cord neurons. Pain. 2004;112(3):315-23.

15. Fujiwara T, Oda K, Yokota S, Takatsuki A, Ikehara Y. Brefeldin A causes disassembly of the Golgi complex and accumulation of secretory proteins in the endoplasmic reticulum. J Biol Chem. 1988;263(34):18545-52.

16. Bercik P, Verdu EF, Collins SM. Is irritable bowel syndrome a low-grade inflammatory bowel disease? Gastroenterol Clin North Am. 2005;34(2):235-45.

17. Aziz Q. Visceral hypersensitivity: fact or fiction. Gastroenterology, 2006;131(2):661-4.

18. Aloisi AM, Craft RM, Marchand S. The effects of gonadal hormones on pain. in Procedings of the 11th World Congress on Pain. 2006: IASP Press.

19. LeResche L, Mancl L, Sherman JJ, Gandara B, Dworkin SF. Changes in temporomandibular pain and other symptoms across the menstrual cycle. Pain. 2003;106(3):253-61.

20. Fillingim RB, Ness TJ. Sex-related hormonal influences on pain and analgesic responses. Neurosci Biobehav Rev. 2000;24(4):485-501.

21. Houghton LA, Lea R, Jackson N, Whorwell PJ. The menstrual cycle affects rectal sensitivity in patients with irritable bowel syndrome but not healthy volunteers. Gut. 2002;50(4):471-4.

22. Smith YR, Stohler CS, Nichols TE, Bueller JA, Koeppe RA, Zubieta JK. Pronociceptive and antinociceptive effects of estradiol through endogenous opioid neurotransmission in women. J Neurosci. 2006;26(21):5777-85.

23. Sherman JJ, LeResche L. Does experimental pain response vary across the menstrual cycle? A methodological review. Am J Physiol Regul Integr Comp Physiol. 2006;291(2): R245-56

24. Ji Y, Murphy AZ, Traub RJ. Estrogen modulates the visceromotor reflex and responses of spinal dorsal horn neurons to colorectal stimulation in the rat. J Neurosci. 2003;23(9):3908-15

25. Liu B, Eisenach JC, Tong C. Chronic estrogen sensitizes a subset of mechanosensitive afferents innervating the uterine cervix. J Neurophysiol. 2005;93(4):2167-73.

26. Tong C, Ma W, Shin SW, James RL, Eisenach JC. Uterine cervical distension induces cFos expression in deep dorsal horn neurons of the rat spinal cord. Anesthesiology. 2003;99(1):205-11.

27. Yan T, Liu B, Du D, Eisenach JC, Tong C. Estrogen amplifies pain responses to uterine cervical distension in rats by altering transient receptor potential-1 function. Anesth Analg. 2007;104(5):1246-50.

28. Gaumond I, Arsenault P, Marchand S. The role of sex hormones on formalin-induced nociceptive responses. Brain Res. 2002;958(1):139-45.

29. Gaumond I, Arsenault P, Marchand S. Specificity of female and male sex hormones on excitatory and inhibitory phases of formalin-induced nociceptive responses. Brain Res. 2005;1052(1):105-11.

30. Mannino CA, South SM, Quinones-Jenab V, Inturrisi CE. Estradiol replacement in ovariectomized rats is antihyperalgesic in the formalin test. J Pain. 2007;8(4):334-42.

31. Leventhal L, Brandt MR, Cummons TA, Piesla MJ, Rogers KE, Harris HA. An estrogen receptor-beta agonist is active in models of inflammatory and chemical-induced pain. Eur J Pharmacol. 2006;553(1-3):146-8.

32. Sanoja R, Cervero F. Estrogen-dependent abdominal hyperalgesia induced by ovariectomy in adult mice: a model of functional abdominal pain. Pain. 2005;118(1-2):243-53.

33. Sanoja R, Cervero F. Estrogen modulation of ovariectomy-induced hyperalgesia in adult mice. Eur J Pain. 2008;12(5):573-81. 